\title{
IMIII Gender, Race, and Variation in the Evaluation of Microscopic Hematuria Among Medicare Beneficiaries
}

Jeffrey C. Bassett, MD, MPH ${ }^{1,2}$, JoAnn Alvarez, MA ${ }^{3}$, Tatsuki Koyama, PhD', Matthew Resnick, $M D^{1,2}$, Chaochen You, $\mathrm{MD}^{7}$, Shenghua Ni, $\mathrm{PhD}^{7}$, David F. Penson, MD, MPH ${ }^{1,2}$, and Daniel A. Barocas, MD, $\mathrm{MPH}^{1,2}$

'Department of Urologic Surgery, Vanderbilt University Medical Center, Nashville, TN, USA; ${ }^{2}$ Center for Surgical Quality and Outcomes Research, Vanderbilt University, Nashville, TN, USA; ${ }^{3}$ Department of Biostatistics, Vanderbilt University School of Medicine, Nashville, TN, USA.

BACKGROUND: Female gender and black race are associated with delayed diagnosis and inferior survival in patients with bladder cancer.

OBJECTIVE: We aimed to determine the association between gender, race, and evaluation of microscopic hematuria (an early sign of bladder cancer).

DESIGN AND PARTICIPANTS: This was a cohort study using a $5 \%$ random sample of fee-for-service Medicare beneficiaries diagnosed with incident hematuria (International Classification of Diseases, Ninth Revision [ICD-9] code 599.7x) between January 2009 and June 2010 in a primary care setting. Beneficiaries with pre-existing explanatory diagnoses or genitourinary procedures were excluded.

MAIN MEASURES: The main endpoint was completeness of the hematuria evaluation in the 180 days after diagnosis. Evaluations were categorized as complete, incomplete, or absent based on receipt of relevant diagnostic procedures and imaging studies.

KEY RESULTS: In all, 9,211 beneficiaries met the study criteria. Hematuria evaluations were complete in $14 \%$, incomplete in $21 \%$, and absent in $65 \%$ of subjects. Compared to males, females were less likely to have a procedure (26 vs. $12 \%$ ), imaging (41 vs. $30 \%)$, and a complete evaluation (22 vs. $10 \%)$ $(p<0.001$ for each comparison). Receipt of a complete evaluation did not differ by race. Controlling for baseline characteristics, a complete evaluation was less likely in white women (OR, 0.40 [95\% CI, 0.35-0.46]) and black women (OR, 0.46 [95\% CI, 0.29-0.70]) compared to white men; no difference was found between black and white men.

CONCLUSIONS: Women are less likely than men to undergo a complete and timely hematuria evaluation, a finding likely relevant to women's more advanced stage at bladder cancer diagnosis. System-level process improvement between providers of urologic and primary care in the evaluation of hematuria may benefit women harboring malignancy.

KEY WORDS: hematuria; variability in practice; health care disparity; diagnostic evaluation; urinary bladder neoplasms.

Received June 17, 2014

Revised October 3, 2014

Accepted October 27, 2014

Published online December 2, 2014
J Gen Intern Med 30(4):440-7

DOI: $10.1007 / \mathrm{s} 11606-014-3116-2$

() Society of General Internal Medicine 2014

\section{INTRODUCTION}

Disparate bladder cancer outcomes by race and sex persist despite overall improvements in survival in the past 30 years. Among patients diagnosed with bladder cancer between 2003 and 2009 in the United States, 5-year survival was greatest for white males $(82 \%)$, followed in order by white females (76\%), black males (69\%), and black females (54\%). ${ }^{1}$

Hematuria is often the first sign of bladder cancer, portending malignancy $2.3-25.8 \%$ of the time, depending on the cohort evaluated (population vs. referral), severity of hematuria, and patient-level risk factors such as age, gender, and smoking status. $^{2-6}$ The evaluation recommended by the American Urological Association for microscopic hematuria includes cystoscopy and upper tract imaging for those without an obvious benign etiology. ${ }^{7,8}$ Population-based studies suggest that the minority of those with hematuria are evaluated (9-36\%), 9,10 a finding that persists even in those at high risk for malignancy. ${ }^{11}$

The quality of a hematuria evaluation is determined by its completeness and timeliness. Incomplete or untimely evaluations can delay cancer diagnoses, and potentially result in a more advanced stage and worse prognoses. We sought to evaluate the completeness and timeliness of incident microscopic hematuria evaluations in a contemporary cohort of Medicare beneficiaries. Based on the patterns of disparity in bladder cancer, we hypothesized that a complete and timely hematuria evaluation was more likely to occur in whites than blacks, and in males than females.

\section{METHODS}

\section{Database and Study Population}

We performed a retrospective cohort study of fee-for-service Medicare beneficiaries diagnosed with microscopic hematuria between January 2009 and June 2010. We used a $5 \%$ national sample of Medicare inpatient, outpatient, and carrier claims in the Medicare Limited Data Set to identify subjects diagnosed 
with hematuria (International Classification of Diseases, Ninth Revision [ICD-9] codes 599.7x) during the study time frame. The diagnosis of hematuria was required to be from a primary care provider (PCP) (Medicare specialty codes $01,08,11,50$, and 70) in the outpatient setting (verified by Place of Service codes). Subjects were considered for inclusion if they were 66 years of age or older and had continuous Medicare parts A and $\mathrm{B}$ coverage for at least 12 months prior and 6 months after the hematuria diagnosis, allowing us to compute comorbidity and assess for pre-existing diagnoses that would exclude the patient from our study. For subjects with more than one diagnosis of hematuria within the study time frame, the first diagnosis of hematuria was considered the "index" event.

Subjects were excluded if they had gross hematuria (ICD-9 code 599.71), or if their Medicare eligibility was due to chronic kidney disease or disability. To define a cohort whose hematuria was not the sequelae of a known disease state, we excluded beneficiaries with pre-existing nephrourologic diagnoses or conditions. Subjects with a diagnosis of a genitourinary neoplasm or urolithiasis at any point prior to the hematuria diagnosis were excluded. In addition, subjects with a disease process or a genitourinary procedure in the 12 months prior to the hematuria diagnosis that could explain the hematuria were also excluded (determined by ICD-9 and Healthcare Common Procedure Coding System [HCPCS] codes) (see online Appendix 1 for disease process codes and online Appendix 2 for procedure codes used for exclusion criteria).

An institutional data use agreement is in place with the Centers for Medicare and Medicaid Service for use of the analytic files, and the study was deemed exempt by the institutional review board as this was non-human subject research posing little to no risk to study participants.

\section{Outcomes}

The primary endpoint of the study was receipt of a hematuria evaluation. We trichotomized the outcome on the basis of completeness and timeliness. The evaluation was considered 1) complete if the subject had both a genitourinary procedure (primarily cystoscopy) and an abdomino-pelvic imaging study within 6 months of hematuria diagnosis; 2) incomplete if the evaluation comprised either an endoscopic procedure or imaging study within 6 months of hematuria diagnosis; or 3) absent if the patient underwent neither a procedure nor imaging within the 6 months of hematuria diagnosis. Abdomino-pelvic imaging studies included diagnostic ultrasound, urography, computerized axial tomography, and magnetic resonance imaging; consistent with guideline recommendations, plain radiographs were not considered sufficient imaging for the upper tracts. Determination of receipt of relevant procedures and imaging was based on ICD-9 and HCPCS codes from the inpatient, outpatient, and carrier files (see Appendix 2 for ICD-9 and HCPCS procedure codes used to determine receipt of relevant procedures and imaging). The 6-month time frame was chosen based on the established literature, with delays longer than 6 months being associated with adverse outcomes. ${ }^{12,13}$

Secondary endpoints included provider contribution to the hematuria evaluation by type and utility of the hematuria evaluation. Medicare specialty codes were used to determine whether the subject was seen by a urologist (Medicare specialty code 34 ), and whether the urologist performed one of the relevant procedures in the 6 months after hematuria diagnosis. Arrival at a definitive urologic or renal diagnosis within the 6-month time frame was determined using the same ICD-9 codes used for the exclusion criteria (see Appendix 1 for ICD-9 diagnosis codes).

\section{Covariates}

Demographic variables included age, gender, and race. Race was categorized as white, black, and all others, due to the paucity of non-white, non-blacks in our sample. All others included Asian (2\%), Hispanic (1\%), North American Native $(1 \%)$, and other $(1 \%)$. Nine subjects were excluded from all analyses due to unknown race.

Clinical characteristics included subject comorbidity, quantified using the Klabunde adaptation of the Charlson index, ${ }^{14}$ and subject use of tobacco, antiplatelets, or anticoagulants. Tobacco use was determined by ICD-9 and HCPCS codes for smoking history and smoking cessation counseling or treatment (ICD-9: 305.1, V15; HCPCS: C9801, C9802, G0436, G0437, G8686, G8688, G8690, G8692, G8751, G9016, S4995, S9453, S9075). Long-term, current use of antiplatelets or anticoagulants was per ICD-9 codes (V58.61, V58.63, V58.66).

Subject socioeconomic status was inferred from the socioeconomic features of the county of residence. ${ }^{15,16}$ Median household income and education (percent of adults over 25 years old without a high school diploma) were obtained by linking the subjects' Federal Information Processing Standard county codes to the Area Resource File (ARF). ${ }^{17}$

In order to account for the setting of healthcare delivery, environmental characteristics, including percent urban (vs. rural) and density of providers (primary care and urologic) per 100,000 residents, were obtained from the ARF. The Medicare region of subject residence was categorized as Northeast, South, Central, or West.

\section{Statistical Analysis}

Standard descriptive statistics were used to describe the cohort. Pearson chi-squared tests were used to evaluate bivariate associations between race, gender, and the primary and secondary endpoints.

We fit generalized linear mixed models (GLMM) to examine the relationship between race-gender strata and the completeness of hematuria evaluation, adjusting for the demographic, clinical, socioeconomic, and environmental covariates. Since the workup quality measure (absent, incomplete, complete) is ordinal, we used a proportional odds logistic regression. Characteristics of the individual subjects were treated as fixed effects. A restricted cubic spline with three 
knots was used for age to permit nonlinearity. A random intercept for the subject's county of residence was used to account for homogeneity among provider practices within the same county. As the influence of race on the outcomes likely varies by gender and region, we included interaction terms a priori between race and sex, as well as race and region.

Chi-squared tests were used to compare the practice patterns of PCPs (referring to a urologist) and the urologists (performing a relevant procedure) by race and gender.

All analyses were performed using R Version 3.0.2 (R Core Team).

\section{RESULTS}

Over the eighteen consecutive months ending June 2010, 9,211 Medicare beneficiaries met our study inclusion criteria. Baseline characteristics of our cohort are displayed in Table 1. The median age was 74 years (interquartile range [IQR]: 69 $81)$, with the majority of the cohort being female $(72 \%)$ and white $(89 \%)$.

Components and completeness of hematuria evaluation by gender and race can be seen in Table 2. Overall, the hematuria evaluation was complete in $14 \%$, incomplete in $21 \%$, and absent in $65 \%$. Women were less likely than men to undergo a procedure (12 vs. $26 \%, p<0.001)$ or abdomino-pelvic

Table 1. Characteristics of Medicare Beneficiaries Diagnosed with Incident Hematuria in a Primary Care Setting $(N=9,211)$

\begin{tabular}{|c|c|}
\hline \multicolumn{2}{|l|}{ Demographic characteristics } \\
\hline Age in years, median (IQR) & $74(69-81)$ \\
\hline \multicolumn{2}{|l|}{ Gender, No. $(\%)$} \\
\hline Female & $6,669(72)$ \\
\hline \multicolumn{2}{|l|}{ Race/ethnicity, No. (\%) } \\
\hline White & $8,238(89)$ \\
\hline Black & $538(6)$ \\
\hline All others* & $435(5)$ \\
\hline \multicolumn{2}{|l|}{ Clinical characteristics } \\
\hline \multicolumn{2}{|l|}{ Charlson comorbidity index, No. (\%) } \\
\hline 0 & $929(10)$ \\
\hline $1-2$ & 4,085 (44) \\
\hline $3-4$ & $2,424(26)$ \\
\hline$\geq 5$ & $1,773(19)$ \\
\hline Tobacco use (yes), No. (\%) & $726(8)$ \\
\hline Anticoagulation (yes), No. (\%) & $1,143(12)$ \\
\hline \multicolumn{2}{|l|}{ Socioeconomic and environmental characteristics ${ }^{\dagger}$} \\
\hline $\begin{array}{l}\text { Household income in thousands (\$), median } \\
\text { (IQR) }\end{array}$ & $48.2(41.4-57.6)$ \\
\hline $\begin{array}{l}\% \text { adults without high school education, median } \\
\text { (IQR)** }\end{array}$ & $13.2(10.5-16.9)$ \\
\hline \multicolumn{2}{|l|}{ Region } \\
\hline Northeast & $1,706(19)$ \\
\hline Central & $2,274(25)$ \\
\hline South & $3,397(37)$ \\
\hline West & $1,834(20)$ \\
\hline$\%$ urban population, median (IQR) & $88.3(63.1-97.2)$ \\
\hline $\begin{array}{l}\text { No. of PCPs per } 100,000 \text { residents, median } \\
\text { (IQR) }\end{array}$ & $70.8(54.2-88.3)$ \\
\hline $\begin{array}{l}\text { No. of urologists per } 100,000 \text { residents, median } \\
\text { (IQR) }\end{array}$ & $3.1(1.7-4.5)$ \\
\hline
\end{tabular}

$I Q R$ interquartile range; $P C P$ primary care provider

* Others includes Asian $(n=162)$, Hispanic $(n=128)$, North American Native $(n=23)$, and other $(n=122)$

* Characteristics are county level, derived from linking the subject county code to data from the Area Resource File imaging ( $30 \%$ vs. $41 \%, p<0.001)$ as part of the workup of hematuria. As a result, complete evaluations were less likely in women than men ( $10 \%$ vs. $22 \%, p<0.001)$, with the majority of women ( $69 \%)$ failing to undergo any evaluation. Conversely, completeness of the hematuria evaluation was not shown to differ by race. Whites, blacks, and all others were not found to have different rates of a complete, incomplete, or absent workup for hematuria $(p=0.89)$, or dissimilar rates of procedures and imaging across racial groups.

The results of our multivariable models for race and gender are in Table 3. After controlling for the demographic, clinical, socioeconomic, and environmental characteristics, white and black women were less likely to have a procedure, imaging, or a complete workup for hematuria compared to white men. In contrast, we did not find that black men had rates of complete evaluation, procedures, or imaging that differed from those of white men.

The magnitude of the effect of gender and race on the hematuria evaluation is illustrated in Fig. 1. Taking a white female as an example, the probability of her having a procedure, imaging, or a complete workup is similar to that of a black female, but significantly less than that of a white male. Consolidating the model by utilizing a multinomial outcome for evaluation completeness (i.e., complete, incomplete, and absent) resulted in similar findings (data not shown).

Practice patterns of PCPs and urologists can be seen in Table 4 . Overall, $23 \%$ of subjects were referred to a urologist after the diagnosis of hematuria. Of these, $66 \%$ underwent cystoscopy or other relevant procedures by the urologist, with urologists performing $98 \%(1,401 / 1,436)$ of the procedures received by the cohort. The likelihood of referral to a urologist varied by gender and race. Conversely, among those referred to urologists, no evidence of difference by gender or race was found in the likelihood of the urologist performing a procedural evaluation. Tobacco use did not impact the likelihood of urologic referral or the likelihood of procedural evaluation.

Complete evaluation was more likely to result in a definitive diagnosis than incomplete and absent evaluations (69\% vs. $34 \%$ vs. $8 \%$, respectively; $p<0.001)$. Of the urinary tract neoplasms identified, $81 \%(327 / 403)$ were the result of complete evaluations, as were $88 \%(235 / 267)$ of the bladder cancer diagnoses. For beneficiaries who underwent any procedural or imaging evaluation (incomplete or complete), men were roughly twice as likely as women to be diagnosed with a urologic (non-prostate) malignancy.

\section{DISCUSSION}

Women and blacks experience worse survival after bladder cancer diagnosis, in large part because delayed diagnoses lead to a higher stage at presentation. ${ }^{1,18-21}$ Equalization of tumor stage at diagnosis could reduce this survival disparity; studies adjusting for the more advanced stage at diagnosis of blacks and women eliminate up to $70 \%$ of the excess mortality for 
Table 2. Evaluation of Hematuria by Race and Gender

\begin{tabular}{|c|c|c|c|c|c|c|c|}
\hline & \multicolumn{4}{|l|}{ Race } & \multicolumn{3}{|l|}{ Gender } \\
\hline & $\begin{array}{l}\text { White } \\
(n=8,238)\end{array}$ & $\begin{array}{l}\text { Black } \\
(n=538)\end{array}$ & $\begin{array}{l}\text { All others* } \\
(n=435)\end{array}$ & $P$ & $\begin{array}{l}\text { Male } \\
(n=2,542)\end{array}$ & $\begin{array}{l}\text { Female } \\
(n=6,669)\end{array}$ & $P$ \\
\hline \multicolumn{8}{|c|}{ Components of evaluation ${ }^{\dagger}$} \\
\hline Procedure (yes) & $1,307(16)$ & $74(14)$ & $55(13)$ & 0.09 & $666(26)$ & $770(12)$ & $<0.001$ \\
\hline Imaging (yes) & $2,698(33)$ & $181(34)$ & $153(35)$ & 0.54 & $1,048(41)$ & $1,984(30)$ & $<0.001$ \\
\hline \multicolumn{8}{|c|}{ Completeness of evaluation } \\
\hline Absent & $5,369(65)$ & $347(64)$ & $271(62)$ & 0.89 & $1,391(55)$ & 4,596 (69) & $<0.001$ \\
\hline Incomplete & $1,733(21)$ & $127(24)$ & $120(28)$ & & $588(23)$ & $1,392(21)$ & \\
\hline Complete & $1,136(14)$ & $64(12)$ & $44(10)$ & & $563(22)$ & $681(10)$ & \\
\hline
\end{tabular}

* All others includes Asian, Hispanic, North American Native and other

+ Medicare beneficiaries with incident hematuria were evaluated for receipt of the two components of a hematuria evaluation (procedure and imaging) within 6 months after hematuria diagnosis

$\neq$ Completeness of a subject's hematuria evaluation was categorized as complete, incomplete, or absent, based on the components received within the first 6 months after diagnosis. A subject was determined to have received: 1) a complete evaluation if both a procedure and an imaging study were done; 2) an incomplete evaluation if either a procedure or an imaging study were done; and 3) an absent evaluation if neither a procedure nor an imaging study were done

blacks compared to whites (and black females compared to black males) and $30 \%$ of the excess hazard for white females compared to white males. ${ }^{21-23}$

Our study of Medicare beneficiaries aged 66 years or older has two important findings relevant to tumor burden at diagnosis. First, we found that women are less likely than men to undergo a complete and timely evaluation for hematuria, a finding that remained true when controlling for relevant demographic, clinical, socioeconomic, and environmental characteristics. This was most attributable to the procedural element of the hematuria evaluation; white and black males were more than twice as likely to have a procedure compared to white or black females.

This difference in procedural rates between men and women may underlie the observed gender disparity in the pathologic stage at bladder cancer diagnosis, and subsequently, bladder-cancer-specific survival. The diagnosis of bladder cancer requires a procedure, i.e., endoscopic visualization and biopsy of the bladder wall. For women in whom hematuria is the first sign of malignancy, incomplete or untimely procedural evaluation of the bladder represents a missed opportunity for earlier detection and less advanced disease.

Secondly, and contrary to our hypothesis, we did not find evidence that completeness of the hematuria evaluation varied by race. While blacks in our patient sample received slightly fewer procedural evaluations than whites, we found no statistically significant differences between black and white Medicare beneficiaries with respect to the completeness of hematuria evaluation or in the individual components of evaluation, findings that suggest the evaluation of hematuria may not be the predominant contributor to the advanced tumor burden seen in black-white comparisons within each sex.

Factors antecedent, within, or downstream to the hematuria evaluation merit consideration. Access and utilization of primary care differ by race. ${ }^{24,25}$ Less favorable access and utilization of primary care among black bladder cancer patients has been associated with advanced disease and worse survival compared to whites. ${ }^{18,26}$ Blacks are more likely than whites to have aggressive histologic variants that result in a worse prognosis even with adjustment for grade, stage, and treatment. ${ }^{18,23,26,27}$ Blacks are less likely to undergo definitive surgery, more likely to be treated by low-volume providers and in low-volume hospital settings, and more likely to experience adverse treatment-related outcomes. ${ }^{28-32}$ While our data showed that black patients who accessed care were as equally likely as whites to undergo complete hematuria evaluations, our ability to identify differences in health system engagement between races is limited by the obvious selection bias inherent to claims data of insured individuals.

With regard to our secondary endpoints, we found that primary care practice patterns largely accounted for the observed sex-based variation in procedural evaluation. PCPs were twice as likely to refer men with hematuria to a urologist, whereas urologists were as likely to perform a procedure regardless of sex. Our data also demonstrate an association

Table 3. Model-Based Expected Odds Ratios of Hematuria Evaluation for Race-Gender Groups*

\begin{tabular}{lc}
\hline \hline & Odds ratio $\mathbf{( 9 5} \% \mathbf{C l})$ \\
\hline Procedure & \\
White male & 1.00 (referent) \\
Black male & $1.10(0.67-1.79)$ \\
White female & $0.37(0.33-0.42)$ \\
Black female & $0.38(0.25-0.58)$ \\
Imaging & \\
White male & $1.00($ referent) \\
Black male & $0.84(0.56-1.26)$ \\
White female & $0.59(0.53-0.65)$ \\
Black female & $0.75(0.56-1.01)$ \\
Complete evaluation & \\
White male & $1.00($ referent) \\
Black male & $1.21(0.72-2.01)$ \\
White female & $0.40(0.35-0.46)$ \\
Black female & $0.46(0.29-0.70)$ \\
\hline PCP primary care provider & \\
$*$ Comparisons to white males. Estimates are from the multivariable \\
models that control for age, household income, education, comorbidity, \\
tobacco use, anticoagulation, region, \% urban, and number of PCPs \\
and urologists per 100,000 residents. Estimated odds ratios vary by \\
region; the values presented are computed for the most frequent region \\
in our data (i.e., South)
\end{tabular}



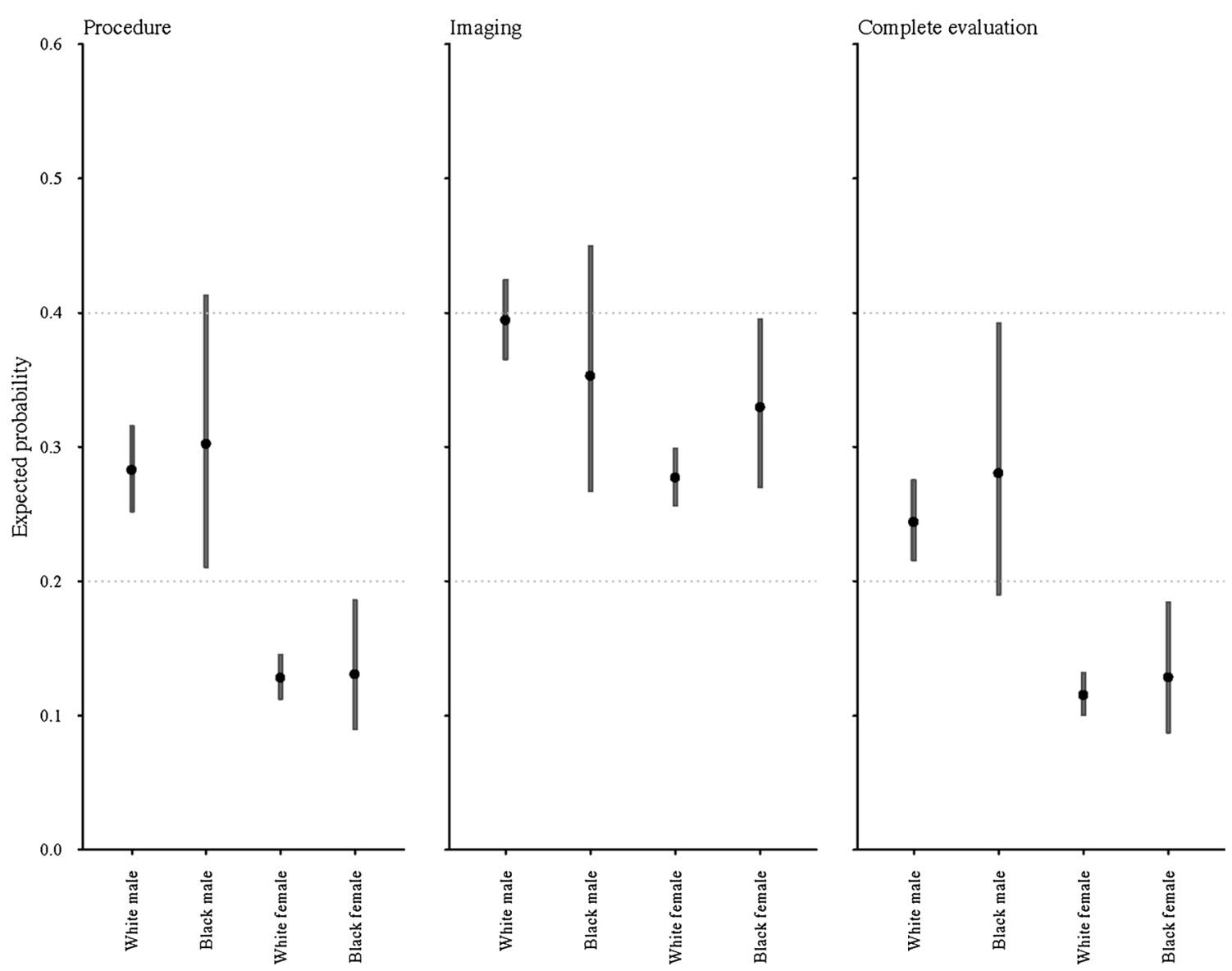

Figure 1. Estimated expected probability of evaluation outcomes by race-gender strata. Expected probabilities of receiving a component of hematuria evaluation (i.e., procedure or imaging) and both components (i.e., complete evaluation). Expected probabilities computed from multivariable models with baseline demographic, clinical, socioeconomic, and environmental characteristics set to medians/modes.

between the completeness of the hematuria evaluation and the likelihood of an explanatory diagnosis; complete evaluations were two and eight times more likely to have an etiologic diagnosis as incomplete and absent evaluations, respectively.

These findings are neither an indictment of PCPs nor congratulatory of urologists. While it may be that optimal use of hematuria evaluations would result in more women undergoing procedural evaluation, reaching this conclusion from our data would be a post hoc fallacy. Variation in referral to specialty providers is dependent on a number of complex patient, provider, and environmental factors that cannot be discerned from an administrative data set. ${ }^{33,34}$ In the context of the hematuria evaluation, the lower referral rate of women to urologists likely reflects appropriate risk stratification by PCPs. Women are more likely to have obvious benign causes of hematuria, including urinary tract infection and menstruation, which do not require procedural evaluation. Bladder cancer is three times more common in men, ${ }^{35}$ a higher referral rate therefore commensurate with cancer risk. It may also be that the rate of procedural evaluations by urologists should differ by gender or race, as opposed to being similar as shown in our data.

Yet for women in whom hematuria is the first indication of bladder cancer, repeated empiric treatment of urinary tract infections (UTIs) and voiding symptoms results in delayed diagnoses and more advanced disease. In a recent study, a

Table 4. Referral to Urologist and Subsequent Procedure by Urologist as Part of the Hematuria Evaluation*

\begin{tabular}{|c|c|c|c|c|}
\hline & $\begin{array}{l}\text { Referred to } \\
\text { urologist by PCP } \\
(n=9,211)\end{array}$ & $P$ & $\begin{array}{l}\text { Procedure by } \\
\text { urologist }^{\dagger} \\
(n=2,124)\end{array}$ & $P$ \\
\hline \multicolumn{5}{|l|}{ Race/Ethnicity } \\
\hline $\begin{array}{l}\text { White } \\
\quad(n=8,238)\end{array}$ & $1,917(23)$ & 0.03 & $1,275(67)$ & 0.10 \\
\hline $\begin{array}{l}\text { Black } \\
(n=538)\end{array}$ & $129(24)$ & & $74(57)$ & \\
\hline $\begin{array}{l}\text { All others } \\
(n=435)\end{array}$ & $78(18)$ & & $52(67)$ & \\
\hline \multicolumn{5}{|l|}{ Gender } \\
\hline $\begin{array}{l}\text { Male } \\
(n=2,542)\end{array}$ & $983(39)$ & $<0.001$ & $656(67)$ & 0.49 \\
\hline $\begin{array}{l}\text { Female } \\
(n=6,669)\end{array}$ & $1,141(17)$ & & $745(65)$ & \\
\hline \multicolumn{5}{|c|}{$\begin{array}{l}\text { PCP primary care provider } \\
* \text { Medicare specialty codes were used to determine if 1) the PCP } \\
\text { referred the patient to a urologist after the diagnosis of hematuria; and } \\
\text { 2) if the urologist subsequently performed a procedure as part of their } \\
\text { evaluation } \\
+ \text { Out of total number of patients referred to urologists by PCPs (n= } \\
2,124 \text { ) } \\
+ \text { All others includes Asian, Hispanic, North American Native, and other }\end{array}$} \\
\hline
\end{tabular}


billing claim for UTI was the strongest predictor of a longer interval between presentation with hematuria and bladder cancer diagnosis in a cohort of commercially insured patients under the age 65 years. ${ }^{36}$ Similarly, adjusted analyses from the National Cancer Experience Survey in England demonstrated that, out of seventeen malignancies studied, the interaction between sex and delayed referral was strongest for women with bladder cancer. ${ }^{37}$

The logical question is how to appropriately balance timely identification of malignancy in those in whom it is less likely (women and blacks) without increasing unnecessary evaluation in those in whom it is likely lower yield. Increasing collaboration among providers, improved risk stratification, and the introduction of system-level measures to reduce variability hold promise. Physician-led collaboration in genitourinary cancers has demonstrated the ability to inform observational findings from administrative data sets, improve quality, and optimize utilization. ${ }^{38-40}$ Similarly, the hematuria risk index developed within Kaiser Permanente is progress towards evidence-based determination of the appropriateness of a hematuria evaluation based on individualized risk. ${ }^{41}$ Whether payment reform will enhance efforts to target hematuria evaluations to those at highest risk for significant pathology remains to be seen.

Our study has limitations. Our cohort consisted of Medicare beneficiaries aged $\geq 66$ years, and our findings may not be generalizable to younger patients or cohorts with more heterogeneity in insurance status. While almost $75 \%$ of bladder cancer diagnoses in the U. S. occur in the Medicare population, ${ }^{1}$ gender and race disparities in those of a younger age may not be represented in our findings. Secondly, there may be imperfectly measured and unmeasured characteristics that could account for some of our findings regarding gender and race. We tried to mitigate this by using established methods to control for known contributors to disparity in urinary tract malignancies that could be measured, and we chose our inclusion and exclusion criteria to favor the creation of a homogenous cohort. Third, our results are not adjusted for hematuria severity, as a quantified measure is not available in our data set (i.e., number of red blood cells per high-power field on microscopic examination). Fourth, we are unable to account for patient-level preferences regarding undergoing an evaluation for hematuria; trust and confidence in providers and the healthcare system is known to vary by race and gender. ${ }^{42,43}$ Lastly, the completeness and timeliness of a hematuria evaluation is but one of many factors that may contribute to the disparate survival outcomes in bladder cancer.

Despite these limitations, our results demonstrate that in a cohort of Medicare beneficiaries with incident hematuria, receipt of a complete and timely hematuria evaluation was less likely in women than men and of similar likelihood in blacks and whites. Collaborative efforts aimed at improving the quality of evaluation in at-risk women should yield a stage migration toward less advanced disease, and should meaningfully impact disparate bladder cancer outcomes.

\section{Acknowledgements:}

Contributors: None.

Funding/Support: This study was funded by a grant from the National Cancer Institute to study variation in evaluation for hematuria (1R03CA173807-01; Barocas PI).

Previous Presentation: Portions of this study were presented at the American Urological Association Annual Meeting (17 May 2014, Orlando, Florida) and at the American College of Surgeons Annual Meeting (27 October 2014, San Francisco, California).

Conflict of Interest: The authors declare that they do not have any conflicts of interest. Dr. Barocas is a paid consultant for GE Healthcare; however, this is not related in any way to the current submission.

Corresponding Author: Jeffrey C. Bassett, MD, MPH; Department of Urologic SurgeryVanderbilt University Medical Center, A1302 Medical Center North, Nashville, TN 37232-2765, USA (e-mail: jeffrey.c.bassett@kp.org).

\section{REFERENCES}

1. Howlander N, Noone AM, Krapcho M, et al. SEER Cancer Statistics Review, 1975-2010, National Cancer Institute. Bethesda, MD; Available at: http://seer.cancer.gov/csr/1975_2010/. Retrieved October 30, 2014.

2. Mohr DN, Offord KP, Owen RA, Melton LJ 3rd. Asymptomatic microhematuria and urologic disease. A population-based study. JAMA. 1986;256(2):224-9.

3. Mariani AJ, Mariani MC, Macchioni C, Stams UK, Hariharan A, Moriera A. The significance of adult hematuria: 1,000 hematuria evaluations including a risk-benefit and cost-effectiveness analysis. J Urol. 1989;141(2):350-5.

4. Messing EM, Young TB, Hunt VB, Wehbie JM, Rust P. Urinary tract cancers found by homescreening with hematuria dipsticks in healthy men over 50 years of age. Cancer. 1989;64(11):2361-7.

5. Sultana SR, Goodman CM, Byrne DJ, Baxby K. Microscopic haematuria: urological investigation using a standard protocol. $\mathrm{Br} \mathrm{J}$ Urol. 1996;78(5):691-696. discussion 697-8.

6. Khadra MH, Pickard RS, Charlton M, Powell PH, Neal DE. A prospective analysis of 1,930 patients with hematuria to evaluate current diagnostic practice. J Urol. 2000;163(2):524-7.

7. Grossfeld GD, Litwin MS, Wolf JS Jr, et al. Evaluation of asymptomatic microscopic hematuria in adults: the American Urological Association best practice policy-part II: patient evaluation, cytology, voided markers, imaging, cystoscopy, nephrology evaluation, and follow-up. Urology. 2001;57(4):604-10.

8. Davis R, Jones JS, Barocas DA, et al. Diagnosis, evaluation and follow-up of asymptomatic microhematuria (AMH) in adults: AUA guideline. J Urol. 2012;188(6 Suppl):2473-81.

9. Buteau A, Seideman CA, Svatek RS, et al. What is evaluation of hematuria by primary care physicians? Use of electronic medical records to assess practice patterns with intermediate follow-up. Urol Oncol. 2014;32(2): 128-34.

10. Friedlander DF, Resnick MJ, You C, et al. Variation in the Intensity of Hematuria Evaluation: A Target for Primary Care Quality Improvement. Am J Med. Jan 282014.

11. Elias K, Svatek RS, Gupta S, Ho R, Lotan Y. High-risk patients with hematuria are not evaluated according to guideline recommendations. Cancer. 2010;116(12):2954-9.

12. Hollenbeck BK, Dunn RL, Ye Z, et al. Delays in diagnosis and bladder cancer mortality. Cancer. 2010;116(22):5235-42.

13. Cohn JA, Vekhter B, Lyttle C, Steinberg GD, Large MC. Sex disparities in diagnosis of bladder cancer after initial presentation with hematuria: A nationwide claims-based investigation. Cancer. 2014;120(4):555-61.

14. Klabunde CN, Potosky AL, Legler JM, Warren JL. Development of a comorbidity index using physician claims data. J Clin Epidemiol. 2000;53(12): 1258-67.

15. Krieger N. Overcoming the absence of socioeconomic data in medical records: validation and application of a census-based methodology. Am J Public Health. 1992;82(5):703-10. 
16. Krieger N, Williams DR, Moss NE. Measuring social class in US public health research: concepts, methodologies, and guidelines. Annu Rev Public Health. 1997; 18:341-78.

17. Area Resurce File (ARF); National county-level Health Resource Information Database. 2012; Available at: http://ahrf.hrsa.gov/. Retrieved October 30, 2014.

18. Prout GR Jr, Wesley MN, Greenberg RS, et al. Bladder cancer: race differences in extent of disease at diagnosis. Cancer. 2000;89(6):134958.

19. Cardenas-Turanzas M, Cooksley C, Pettaway CA, Sabichi A, Grossman HB, Elting L. Comparative outcomes of bladder cancer. Obstet Gynecol. 2006;108(1):169-75.

20. Lee CT, Dunn RL, Williams C, Underwood W 3rd. Racial disparity in bladder cancer: trends in tumor presentation at diagnosis. J Urol. Sep. 2006;176(3):927-933. discussion 933-24.

21. Mallin K, David KA, Carroll PR, Milowsky MI, Nanus DM. Transitional cell carcinoma of the bladder: racial and gender disparities in survival (1993 to 2002), stage and grade (1993 to 2007). J Urol. May. 2011;185(5):1631-6.

22. Mungan NA, Aben KK, Schoenberg MP, et al. Gender differences in stageadjusted bladder cancer survival. Urology. 2000;55(6):876-80.

23. Scosyrev E, Noyes $\mathbf{K}$, Feng $\mathbf{C}$, Messing E. Sex and racial differences in bladder cancer presentation and mortality in the US. Cancer. 2009;115(1):68-74.

24. Institute of Medicine. Coverage Matters: Insurance and Health Care Washington: National Academies Press; 2001.

25. Institute of Medicine. Unequal Treatment: Confronting Racial and Ethnic Disparities in Health Care. Washington: National Academies Press; 2002.

26. Prout GR Jr, Wesley MN, McCarron PG, et al. Survival experience of black patients and white patients with bladder carcinoma. Cancer. 2004;100(3):621-30.

27. Bach PB, Schrag D, Brawley OW, Galaznik A, Yakren S, Begg CB. Survival of blacks and whites after a cancer diagnosis. JAMA. 2002;287(16):2106-13.

28. Taub DA, Hollenbeck BK, Cooper KL, et al. Racial disparities in resource utilization for cystectomy. Urology. 2006;67(2):288-93.

29. Konety BR, Allareddy V, Carroll PR. Factors affecting outcomes after radical cystectomy in African Americans. Cancer. 2007;109(3):542-8.

30. Barocas DA, Alvarez J, Koyama T, et al. Racial variation in the quality of surgical care for bladder cancer. Cancer. 2014;120(7):1018-25.

31. Konety BR, Joslyn SA. Factors influencing aggressive therapy for bladder cancer: an analysis of data from the SEER program. J Urol. 2003;170(5):1765-71.

32. Fedeli U, Fedewa SA, Ward EM. Treatment of muscle invasive bladder cancer: evidence from the National Cancer Database, 2003 to 2007. J Urol. 2011;185(1):72-8.

33. Franks $\mathbf{P}$, Zwanziger J, Mooney $\mathbf{C}$, Sorbero $\mathbf{M}$. Variations in primary care physician referral rates. Health Serv Res. 1999;34(1 Pt 2):323-9.

34. Franks P, Williams GC, Zwanziger J, Mooney C, Sorbero M. Why do physicians vary so widely in their referral rates? $J$ Gen Intern Med. 2000;15(3):163-8.

35. Siegel R, Naishadham D, Jemal A. Cancer statistics, 2012. CA Cancer J Clin. 2012;62(1):10-29.

36. Johnson EK, Daignault S, Zhang Y, Lee CT. Patterns of hematuria referral to urologists: does a gender disparity exist? Urology. 2008;72(3):498-502. discussion 502-493.

37. Lyratzopoulos G, Abel GA, McPhail S, Neal RD, Rubin GP. Gender inequalities in the promptness of diagnosis of bladder and renal cancer after symptomatic presentation: evidence from secondary analysis of an English primary care audit survey. BMJ Open. 2013;3(6).

38. Miller DC, Murtagh DS, Suh RS, et al. Regional collaboration to improve radiographic staging practices among men with early stage prostate cancer. J Urol. 2011;186(3):844-9.

39. Burks FN, Liu AB, Suh RS, et al. Understanding the use of immediate intravesical chemotherapy for patients with bladder cancer. J Urol. 2012;188(6):2108-13

40. Barocas DA, Liu A, Burks FN, et al. Practice based collaboration to improve the use of immediate intravesical therapy after resection of nonmuscle invasive bladder cancer. J Urol. 2013;190(6):2011-16.

41. Loo RK, Lieberman SF, Slezak JM, et al. Stratifying risk of urinary tract malignant tumors in patients with asymptomatic microscopic hematuria. Mayo Clin Proc. 2013;88(2):129-38.

42. Lillie-Blanton M, Brodie M, Rowland D, Altman D, McIntosh M. Race, ethnicity, and the health care system: public perceptions and experiences. Med Care Res Rev. 2000;57(Suppl 1):218-35.
43. Burgess DJ, Fu SS, van Ryn M. Why do providers contribute to disparities and what can be done about it? J Gen Intern Med. 2004;19(11):1154-9.

\section{APPENDIX 1}

Table 5. International Classification of Disease, Ninth Revision, Clinical Modification (ICD-9- CM) Diagnostic Codes Associated with Hematuria** ${ }^{*}$ Specified

\begin{tabular}{|c|c|}
\hline$\overline{\text { Diagnosis }}^{\dagger}$ & ICD-9 code \\
\hline \multicolumn{2}{|l|}{ Neoplasm } \\
\hline Prostate cancer & 185 \\
\hline Bladder cancer & $188 . \times$ \\
\hline Kidney cancer & $189.0,189.1$ \\
\hline Cancer of other urinary organs & $189.2-189.9$ \\
\hline $\begin{array}{l}\text { Secondary malignant neoplasm of } \\
\text { other specified sites }\end{array}$ & $198.0,198.1,196.2,196.6$ \\
\hline $\begin{array}{l}\text { Benign neoplasm of male genital } \\
\text { organs }\end{array}$ & $222.2,222.8$ \\
\hline $\begin{array}{l}\text { Benign neoplasm of kidney and } \\
\text { other urinary organs }\end{array}$ & $223 . \times, 223.8 \times, 209.64$ \\
\hline $\begin{array}{l}\text { Carcinoma in situ of genitourinary } \\
\text { system }\end{array}$ & $\begin{array}{l}233.4 \text { - } 233.9 \text { (excluding } \\
233.5)\end{array}$ \\
\hline \multicolumn{2}{|l|}{ Urolithiasis } \\
\hline $\begin{array}{l}\text { Calculus of kidney, ureter, or lower } \\
\text { urinary tract }\end{array}$ & $592 . \times, 594 . \times$ \\
\hline \multicolumn{2}{|l|}{ Medical renal and cystic kidney disease } \\
\hline Cystic kidney disease & $753.1 \times$ \\
\hline $\begin{array}{l}\text { Chronic kidney disease, kidney } \\
\text { transplant }\end{array}$ & 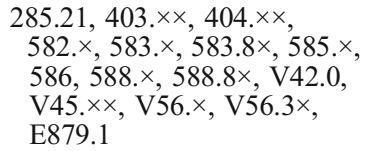 \\
\hline \multicolumn{2}{|l|}{ Hematologic/thrombotic } \\
\hline Sickle cell disease & $282.6 \times$ \\
\hline Coagulation defects & $286 . \times$ \\
\hline \multicolumn{2}{|l|}{ Benign prostatic disease } \\
\hline Hyperplasia of prostate & $\begin{array}{l}600.3,600.0 \times, 600.1 \times \\
600.2 \times, 600.9 \times\end{array}$ \\
\hline Inflammatory disease of prostate & $601 . \times$ \\
\hline Dysplasia of prostate & 602.3 \\
\hline \multicolumn{2}{|l|}{ Infectious and anatomic } \\
\hline Nephritis & $\begin{array}{l}580 . \times, 580.8 \times, 582 . \times \\
582.8 \times, 583 . \times, 583.8 \times\end{array}$ \\
\hline Infections of the kidney & $590 . \times, 590 . \times \times$ \\
\hline Hydronephrosis & 591 \\
\hline Ureteral fistula & 593.82 \\
\hline Cystitis & $595 . \times$ \\
\hline Vesical fistula, NEC & 596.2 \\
\hline Urethritis, not sexually transmitted & $597.0,597.8 \times$ \\
\hline Orchitis and epididymitis & $604.0,604.9 \times$ \\
\hline $\begin{array}{l}\text { Tuberculosis of genitourinary } \\
\text { system }\end{array}$ & $016 . \times$ \\
\hline Schistosomiasis (bilharziasis) & $120 . \times$ \\
\hline \multicolumn{2}{|l|}{ Traumatic or embolic } \\
\hline $\begin{array}{l}\text { Trauma including injury to renal } \\
\text { blood vessels }\end{array}$ & $\begin{array}{l}665.5 \times, 867 . \times, 866 . \times \times \\
902.4 \times\end{array}$ \\
\hline $\begin{array}{l}\text { Other venous embolism and } \\
\text { thrombosis of renal vein }\end{array}$ & 453.3 \\
\hline
\end{tabular}

* ICD-9 codes were used to 1) determine study eligibility (i.e., any potential subject with one or more of the diagnosis codes prior to the hematuria diagnosis was excluded); and 2) in the eligible cohort, determine if a definitive urologic or renal diagnosis was established after the finding of hematuria

+ Potential subjects were deemed ineligible if they had a diagnosis of a neoplasm, urolithiasis, or medical renal and cystic kidney disease at ANY point prior to the hematuria diagnosis, or if they had a diagnosis of a hematologic/thrombotic, benign prostate disease, infectious or anatomic, or traumatic or embolic disease 12 months prior to the hematuria diagnosis

I Specified sites are kidney, other urinary organs, and intra-abdominal pelvic lymph nodes 


\section{APPENDIX 2}

Table 6. International Classification of Disease, Ninth Revision

(ICD-9) and Healthcare Common Procedure Coding System (HCPCS) Procedure and Imaging Codes for Hematuria Evaluation

\begin{tabular}{|c|c|c|}
\hline & ICD-9 code & HCPCS code \\
\hline \multicolumn{3}{|l|}{ Procedure } \\
\hline $\begin{array}{l}\text { Cystoscopy, } \\
\text { cystourethroscopy }\end{array}$ & $\begin{array}{r}56.35,57.31- \\
57.33,57.93 \\
60.94,87.74\end{array}$ & $\begin{array}{l}52000,52001,52005, \\
52007,52010,52204, \\
52214,52224,52234, \\
52235,52240,52250, \\
52260,52265,52270, \\
52275-52277,52281- \\
52283,52285,52287, \\
52290,52300,52301, \\
52305,52310,52315, \\
52320,52325,52327, \\
52330,52332,52334, \\
52341-52343,52400, \\
52402\end{array}$ \\
\hline Ureteroscopy & $56.31,56.33$ & $\begin{array}{l}52344-52346,52351- \\
52355\end{array}$ \\
\hline $\begin{array}{l}\text { Transurethral } \\
\text { resection of prostate }\end{array}$ & $60.2 \times, 60.6 \times$ & $\begin{array}{l}52450,52500,52601 \\
52630,52640\end{array}$ \\
\hline Prostate biopsy & $60.1 \times$ & $55700,55705,55706$ \\
\hline $\begin{array}{l}\text { Nephrectomy } \\
\text { (partial or } \\
\text { complete) }\end{array}$ & $55.4,55.5 \times$ & $\begin{array}{l}50220,50225,50230, \\
50234,50236,50240, \\
50543,50545,50546, \\
50548\end{array}$ \\
\hline $\begin{array}{l}\text { Pyeloplasty, ureteral } \\
\text { anastamosis or } \\
\text { reimplantation }\end{array}$ & $55.86,55.87$ & $\begin{array}{c}50400,50405,50544, \\
50740,50750,50760 \\
50770,50780,50782 \\
50783,50785,50800\end{array}$ \\
\hline Cystectomy & $57.6,57.7 \times$ & $\begin{array}{l}51550,51555,51565, \\
51570,51575,51580, \\
51585,51590,51595- \\
51597\end{array}$ \\
\hline Prostatectomy & $60.3-60.5$ & $\begin{array}{l}55801,55810,55812 \\
55815,55821,55831 \\
55840,55842,55845 \\
55866\end{array}$ \\
\hline \multicolumn{3}{|l|}{ Imaging* } \\
\hline $\begin{array}{l}\text { Diagnostic } \\
\text { ultrasound }\end{array}$ & $88.74-88.76$ & $\begin{array}{l}76700,76705,76770 \text {, } \\
76775\end{array}$ \\
\hline Urography & $87.73-87.75$ & $\begin{array}{l}74400,74410,74415 \\
74420,74425\end{array}$ \\
\hline $\begin{array}{l}\text { Computerized axial } \\
\text { tomography }\end{array}$ & 87.71 & $\begin{array}{l}72192-72194,74150, \\
74160,74170,74176- \\
74178\end{array}$ \\
\hline $\begin{array}{l}\text { Magnetic Resonance } \\
\text { Imaging }\end{array}$ & $88.95,88.97$ & $\begin{array}{l}72195 \text { - 72197, } 74181 \text { - } \\
74185\end{array}$ \\
\hline
\end{tabular}

* All imaging studies are of abdomen, pelvis, or retroperitoneum (including kidneys) 